\title{
CRIMES AMBIENTAIS EM UNIDADE DE PROTEÇÃO INTEGRAL NO SUDOESTE DA AMAZÔNIA
}

Erica Karolina Barros de Oliveira ${ }^{1}$, Augusto César Gomes Nagy $^{2}$, Quétila Souza Barros $^{3}$, Leonidas Soares Murta Júnior ${ }^{1}$, Bianca Cerqueira Martins ${ }^{2}$

${ }^{1}$ Programa de pós-graduação em Ciências Florestais do Departamento de Engenharia Florestal, Faculdade de Tecnologia Universidade de Brasília-UnB (karolina.czs@gmail.com) Brasília/DF-Brasil

${ }^{2}$ Docente do Curso de Engenharia Florestal da Universidade Federal do AcreCâmpus Floresta, Cruzeiro do Sul/Acre-Brasil

${ }^{3}$ Mestre em Ciência Inovação e Tecnologia da Amazônia-UFAC, Rio Branco/ACBrasil

Recebido em: 08/04/2016 - Aprovado em: 30/05/2016 - Publicado em: 20/06/2016 DOI: 10.18677/Enciclopedia_Biosfera_2016_035

\begin{abstract}
RESUMO
Este estudo teve por objetivo analisar os crimes ambientais ocorridos em Unidade de Conservação (UC) de Proteção Integral, da categoria Parque Nacional, localizada no Sudoeste da Amazônia, de modo a apontar o número de operações de fiscalização, quantidade de autos de infração (Al's) lavrados por operação de fiscalização, número de registros por infração, quantidade de áreas embargadas, local e época da apreensão de animais silvestres vivos e abatidos, quantidade do material apreendido (animal vivo e carne), volume em $\left(\mathrm{m}^{3}\right)$ de madeira por espécie e valor total das multas. A metodologia adotada, baseou-se, no levantamento dos Al's que se encontravam arquivados no escritório do Parque Nacional da Serra do Divisor (PNSD), na sede do ICMBio no município de Cruzeiro do Sul- AC, onde foi feita a coleta dos dados e posterior análise dos parâmetros a serem analisados. No período do estudo, de fevereiro de 2011 a dezembro de 2011, foram realizadas 06 operações de fiscalização organizadas pelo ICMBio e outras duas em conjunto com instituições parceiras, houve a lavratura de 71 autos de infração relacionados a crimes ambientais, que totalizaram $R \$ 1.371 .466,00 \mathrm{em}$ multas. A infração de desmatamento foi a mais recorrente durante o período de estudo, seguida do transporte ilegal de animal silvestre. Foram apreendidos $92 \mathrm{Kg}$ de carne de animal silvestre e 29 espécimes, sendo 27 animais vivos e 2 mortos. Apreenderam-se também $41,43 \mathrm{~m}^{3}$ de madeira e foi realizado o embargo de 150,10 hectares de área desmatada. Concluiu-se que: ocorrem muitos ilícitos, que não são registrados devido às dificuldades na fiscalização, que torna-se difícil pela amplitude da área que precisa ser fiscalizada e pelo número reduzido de funcionários nos órgãos de fiscalização.
\end{abstract}

PALAVRAS-CHAVE: Autos de infração; Parque Nacional; Populações tradicionais; 


\title{
ENVIRONMENTAL CRIMES UNIT IN INTEGRAL PROTECTION IN SOUTHWEST AMAZON
}

\begin{abstract}
This study aimed to analyze the environmental crimes in Conservation Unit (UC) of Integral Protection, the National Park category, located in the southwest of the Amazonia, to point the number of surveillance operations, amount of records infringement issued by surveillance operation, number of records per violation, amount of embargoed areas, place and time of the seizure and meat of wild animals, amount of seized material (live animal and meat), volume $\left(\mathrm{m}^{3}\right)$ of timber species seized and the total amount of fines. The methodology adopted was based on the survey of the file that are filed in the office of the Serra do Divisor National Park (PNSD) in ICMBio in county Cruzeiro do Sul-AC, which carried out the data collection and subsequent analysis descriptive of the parameters to be studied. During the study period, there were 06 surveillance operations organized by ICMBio and two together with partner institutions, there was the drawing up of 71 tax assessments (Al's) related to environmental crimes, which totaled $R \$ 1,371,466.00$ in fines. Deforestation offense was the most recurrent during the study period, then the illegal transportation of wild animal. They seized $92 \mathrm{~kg}$ of wild animal meat and 29 specimens, 27 live animals and two dead. It also seized $41.43 \mathrm{~m}^{3}$ of wood and was made the embargo of 150, 10 ha of deforested area. It is indisputable that occur many illicit, which are not recorded due to the difficulties in monitoring, which makes it difficult for the breadth of the area that needs to be monitored and the small number of employees in the supervisory bodies.
\end{abstract}

KEYWORDS: Notices of Violation; National Park; Traditional populations

\section{INTRODUÇÃO}

As Áreas Protegidas (APs), principalmente as Unidades de Conservação (UCs), surgiram como estratégia de ordenamento territorial face à perda da biodiversidade ocorrida em escala mundial (SILVA \& SOUZA, 2015). Neste aspecto apesar do Brasil ser considerado o país mais rico em diversidade biológica do planeta (PLATIAU, 2011) suas APs também seguem a tendência mundial, marcadas por conflitos territoriais que estão longe de serem resolvidos (SILVA \& SOUZA, 2015).

No ano 2000, foi criado o Sistema Nacional de Unidades de Conservação da Natureza (SNUC), pela Lei 9.985/2000 (BRASIL, 2000). Nesse sistema, coexistem Unidades de Proteção Integral (como Parques Nacionais, Reservas Biológicas e outras três categorias), onde apenas é permitido o uso indireto dos recursos naturais, e Unidades de Uso Sustentável (como Reservas Extrativistas, Reservas de Desenvolvimento Sustentável e outras cinco categorias), onde o uso direto é permitido, segundo regras preestabelecidas (COSTA, 2011). O processo de criação de parques e outras unidades de conservação têm sido acompanhados por uma série de conflitos em diferentes partes do mundo, em especial na América Latina, em que estudos revelaram que até a década de 90 até $86 \%$ das áreas protegidas, eram habitadas (KEMF, 1993).

O Parque Nacional da Serra do Divisor (PNSD) no estado do Acre, não é uma exceção a essa tendência ou modelo, embora grande parte da área pertença à União existe um conflito permanente de ocupação por moradores que vivem dentro da unidade (ACRE, 2006). Logo na criação do PNSD, em 16 de junho de 1989, pelo 
Decreto Federal №. 97.839 (BRASIL,1989), o Instituto Nacional de Colonização e Reforma Agrária (INCRA) baixou uma portaria, criando o PAF (Projeto de Assentamento Florestal) Havaí, uma área de 30.000 ha no município de Mâncio Lima/ AC, para alocar os moradores dispostos a sair do Parque. Entretanto, nenhum morador aceitou ir para este local (CAMELY, 2009). Residem no interior do PNSD, aproximadamente 1.000 famílias, as quais sobrevivem dos recursos naturais ali disponíveis (ALMEIDA et al., 2011).

De acordo com o Plano de manejo do PNSD (SOS AMAZÔNIA, 1998), dentre as atividades conflitantes a sua proteção integral destacam-se: a ocupação humana, extrativismo madeireiro e não madeireiro, agricultura, pecuária, desmatamento, criação de animais domésticos, caça e pesca de subsistência e comercial. Atividades essas, que vêm acarretando o surgimento de áreas degradadas no interior da UC (ALMEIDA, 2013).

Este cenário é preocupante, tendo em vista o grande valor ambiental do PNSD, principalmente, por estar localizado no extremo oeste do Brasil, possuindo características peculiares no que se refere a sua vegetação e fauna, o que reforça a sua importância para com a conservação dos recursos presentes na Amazônia (ACRE, 2006). Considerando o exposto, o presente trabalho objetivou analisar os crimes ambientais ocorridos no PNSD no período de fevereiro de 2011 a dezembro de 2011.

\section{MATERIAL E MÉTODOS}

\section{Área de estudo}

A área de estudo foi o PNSD (Figura 1). A mesma está localizada a noroeste do estado do Acre, na fronteira do Brasil com o Peru, entre as coordenadas de longitude 7400' e 72045'W e latitude de 7915' e $9^{\circ}$ 04'S, o PNSD apresenta uma área aproximada de 843.000 ha, abrangendo os municípios de Cruzeiro do Sul, Mâncio Lima, Rodrigues Alves, Porto Walter e Marechal Thaumaturgo (MORATO et al., 2008).



FIGURA 1. Área de abrangência do PNSD, conforme plano de manejo. Base de dados do IBGE. Fonte: adaptado de ALMEIDA (2013) 
O clima é quente e úmido, e a precipitação média anual do PNSD é de 2.200 $\mathrm{mm}$. A temperatura média mensal é de $26^{\circ} \mathrm{C}$ no período chuvoso, podendo diminuir $3^{\circ} \mathrm{C}$ ou $4^{\circ} \mathrm{C}$ no período seco. Quando comparado com ou tras áreas do estado do Acre, a serra do divisor próximo as Cordilheiras dos Andes, na fronteira com o Peru, o clima é mais úmido e frio (SOS AMAZÔNIA, 1998).

O relevo é bastante dissecado com cristas de altitudes de 300 a $600 \mathrm{~m}$, o que torna o acesso e ocupação antrópica bastante difícil. $O$ índice de dissecação é mediano e a intensidade do aprofundamento da drenagem também mediana, variando entre 250 a $600 \mathrm{~m}$. De modo geral, os solos do PNSD são predominantemente Argissolos e Neossolos (SOS AMAZÔNIA, 1998).

O presente estudo é o resultado de uma pesquisa descritiva e documental, fundamentada na coleta de dados que foi realizada entre fevereiro e dezembro de 2011, através do levantamento dos autos de infração lavrados durante operações de fiscalização no PNSD e arquivados pelo ICMBio, no escritório do PNSD, no município de Cruzeiro do Sul- AC.

\section{RESULTADOS E DISCUSSÃO}

A análise revelou que durante o ano de 2011, o ICMBio, lavrou no PNSD um total de 71 Al's, relacionados a crimes ambientais. Deste total 08 foram lavrados na operação Mutum, 18 na Pedernal, 15 na operação Sungarú, 10 na Tamboriaco, 12 autos na Capanauá e 07 na Ipú. Outras duas operações realizadas em conjunto com instituições parceiras, ou seja, Exército Brasileiro, IBAMA e a Polícia Federal, denominadas: Curare e Divisor-Copaíba registraram a lavratura de apenas 01 auto. Dos 71 autos lavrados, 54 foram crimes contra a flora e 17 autos correspondentes a crimes contra a fauna (Figura 2).

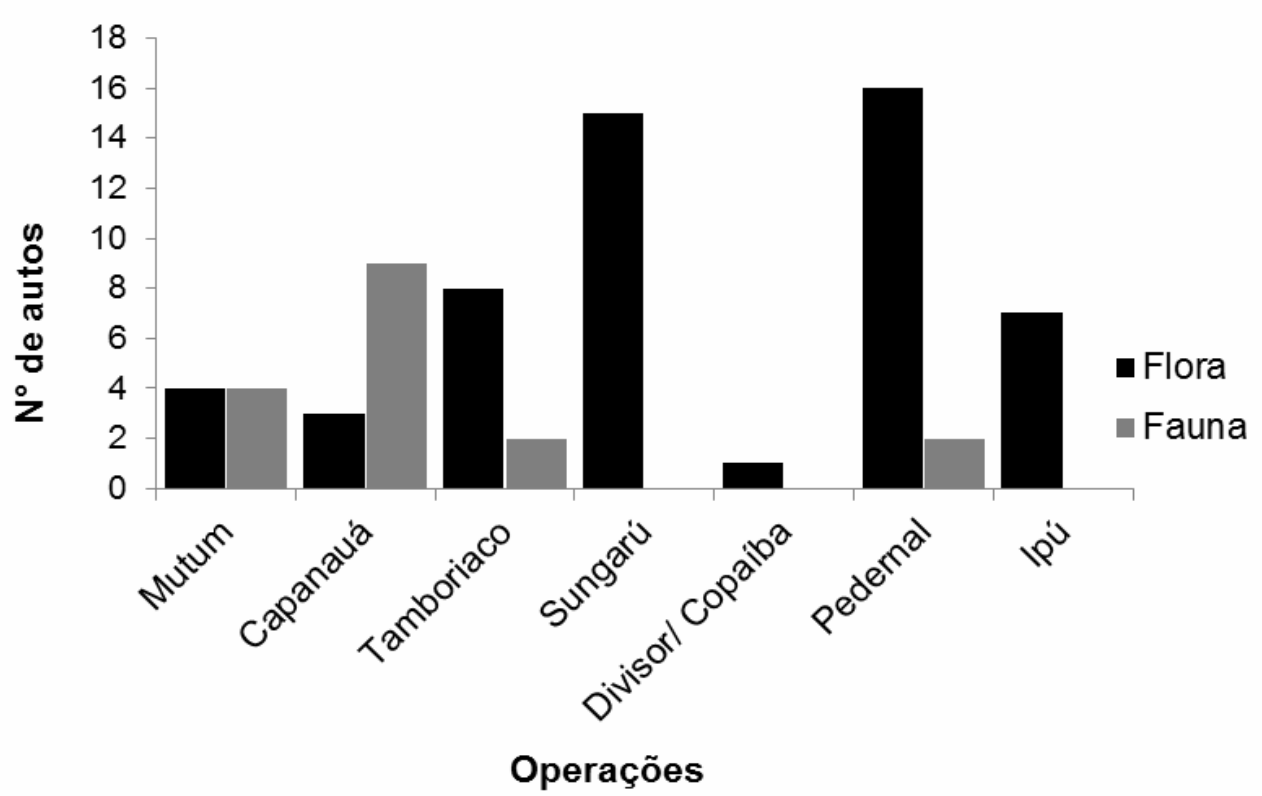

FIGURA 2. Número de autos de infração lavrados por operação no PNSD. Fonte: banco de dados do ICMBio 2011, no prelo. 


\section{Tipologias dos crimes ambientais}

De acordo com os dispositivos legais da Lei 9.605/1998 (Lei de Crimes Ambientais), (BRASIL, 1998) nos autos analisados, o delito ambiental cometido com maior frequência no PNSD foi o desmatamento com 21 registros, que corresponderam a $38,03 \%$ dos casos, seguido do transporte ilegal de animal silvestre, com 20 registros equivalendo a $28,17 \%$, e depósito ilegal de madeira com $16,90 \%$ do total (Figura 3). Na relação de infrações que menos contribuíram para as estatísticas as categorias, corte de árvores protegidas por lei e porte de motosserra sem licença, com apenas 01 registro cada (Figura 3).

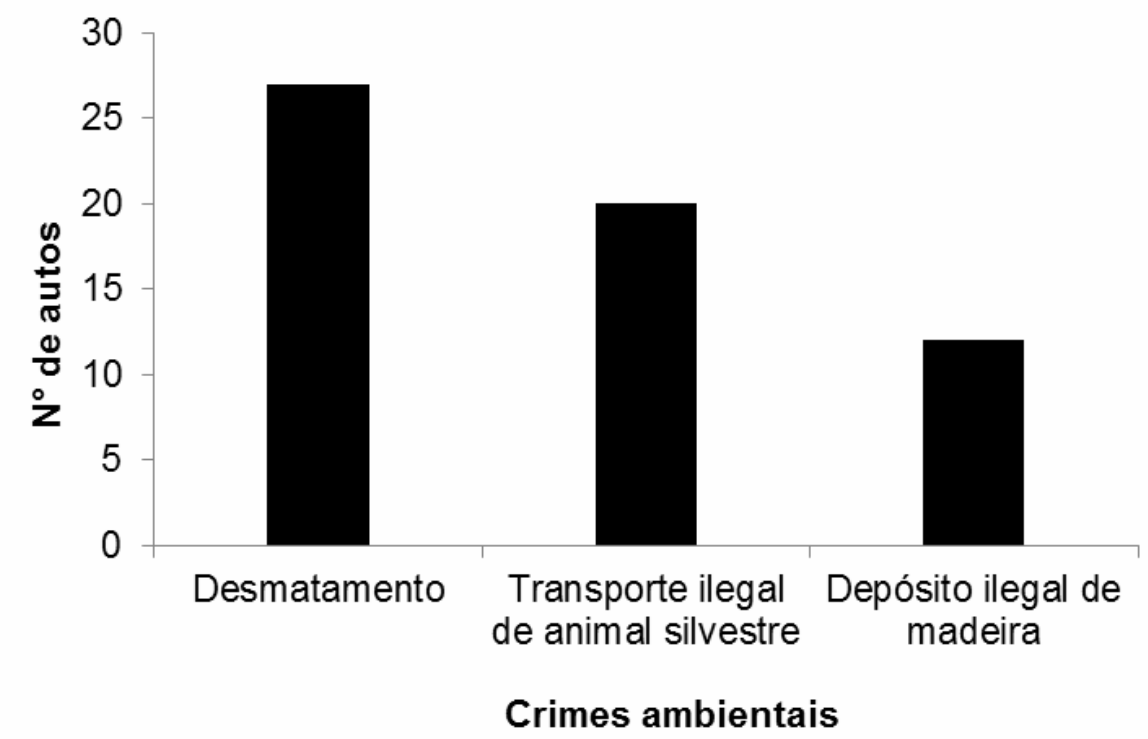

FIGURA 3. Número total dos principais crimes ambientais no PNSD. Fonte: banco de dados do ICMBio 2011, no prelo.

ORTEGA et al., (2012) em estudo sobre os crimes contra a flora no município de Cruzeiro do Sul- AC, verificaram a infração desmatamento, como a mais frequente. Resultado similar foi registrado por FONSECA et al., (2013) que avaliaram os crimes contra a flora no Amazonas no período de 2009 a 2010. BARRETO et al., (2009) analisando a ocorrência de crimes ambientais em Áreas Protegidas no estado do Pará, verificaram a predominância em $76 \%$ dos casos de crimes florestais, incluindo a extração e o transporte ilegal de madeira (59\%) e o desmatamento para abertura de estradas e atividades agropastoris (17\%). LEMOS (2013) registrou o desmatamento como um dos principais crimes ambientais durante verificação da eficácia da aplicação da lei de crimes ambientais para a proteção do meio ambiente no litoral sul da Bahia. O desmatamento significa perda de hábitat para muitas espécies e desequilíbrio dos ecossistemas que a UC pretende preservar (VERÍSSIMO et al., 2011). Os delitos observados, durante a análise dos autos enquadram-se nos Art. 24 e 52 do Decreto 6.514/08 (BRASIL, 2008a) e nos Art. 43, 44 e 49 do Decreto 6.686/08 (BRASIL, 2008b) os quais consideram crime ambiental:

"Desmatar, a corte raso, florestas ou demais formações nativas, fora da reserva legal, sem autorização da autoridade competente (Art. 52.)"; "Matar, perseguir, caçar, apanhar, coletar, utilizar espécimes da fauna silvestre, nativos ou em rota migratória, sem a devida permissão, licença ou autorização da autoridade competente, ou em desacordo com a obtida (Art. 24.)"; "Destruir ou danificar 
florestas ou demais formas de vegetação natural ou utilizá-las com infringência das normas de proteção em área considerada de preservação permanente, sem autorização do órgão competente, quando exigível, ou em desacordo com a obtida (Art. 43)"; "Cortar árvores em área considerada de preservação permanente ou cuja espécie seja especialmente protegida, sem permissão da autoridade competente (Art. 44.)"; Destruir ou danificar florestas ou qualquer tipo de vegetação nativa, objeto de especial preservação, não passíveis de autorização para exploração ou supressão (Art. 49)".

A ocorrência de crimes ambientais em UCs bem como, a ausência de punição aos responsáveis por ocasionar tais danos, pode impulsionar a colonização dessas áreas por meio do desmatamento para a agropecuária. Além disso, essa situação leva à redução ou à tentativa de redução de APs, como vem ocorrendo em Mato Grosso, Roraima, Rondônia e Pará (BARRETO et al., 2009).

O total de áreas embargadas após desmate dentro do PNSD foi equivalente a 150,10 hectares. Deste total, 64,9 ha, ou seja, (43\%) foram embargados durante a operação Pedernal, 39,4 ha $(26 \%)$ na operação Sungarú, 23,1 ha $(15 \%)$ na Tamboriaco, 14,6 ha (10\%) na Ipú, 7,1 ha (5\%) durante a operação Mutum e 1 ha (1\%) durante a operação Capanauá. Nas operações Divisor- Copaíba e Curare, não houve embargo de área (Figura 3).

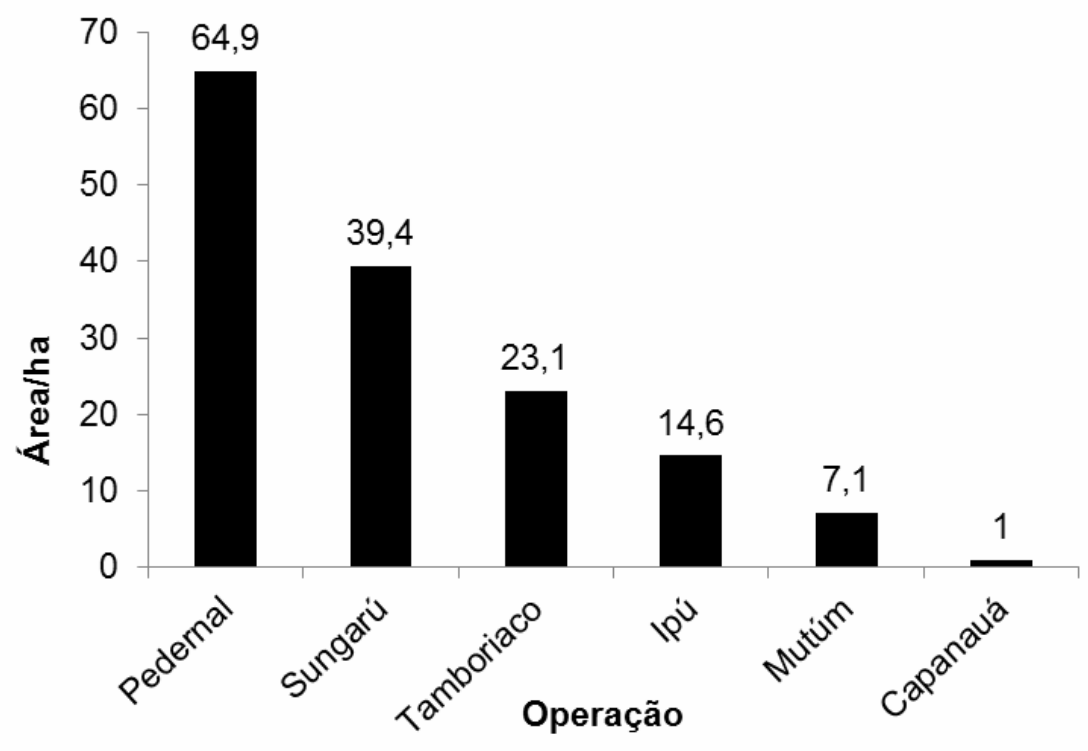

FIGURA 3. Áreas embargadas durante operações de fiscalização no ano de 2011. Fonte: banco de dados do ICMBio 2011, no prelo.

A implantação de roçados e a criação de rebanho bovino pelas populações tradicionais constituem-se, como os principais responsáveis pelo desmatamento do PNSD (Figuras 4 e 5). De acordo com ALMEIDA (2013), essas atividades acarretaram o surgimento de áreas degradadas que totalizam mais de $9 \%$ (75 mil ha) do território da UC. 


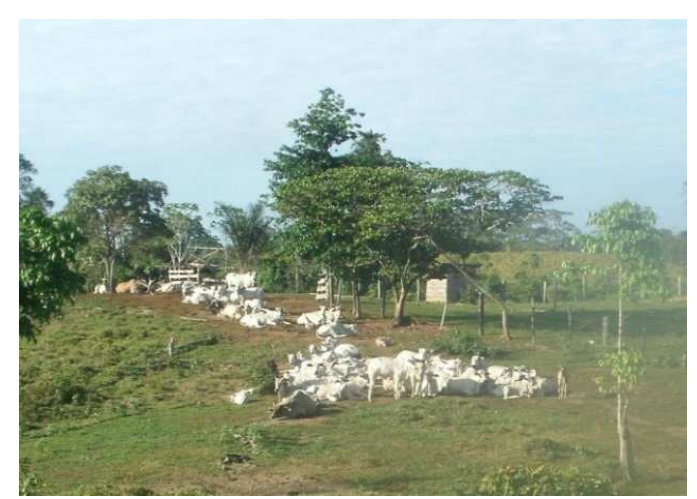

FIGURA 4. Criação de rebanho bovino dentro do PNSD. Fonte: ICMBio.

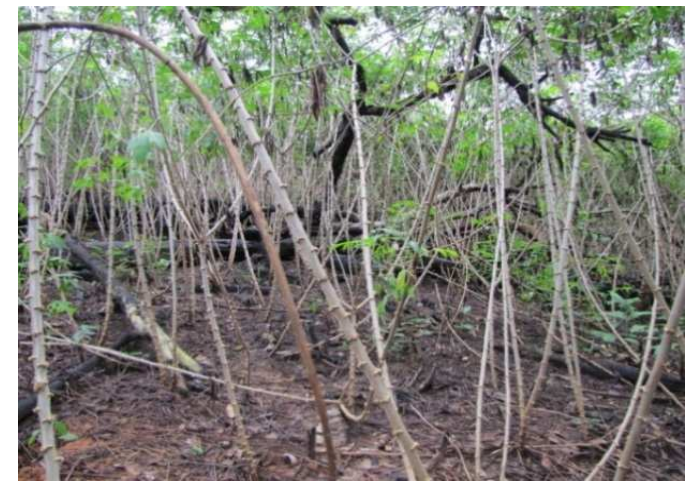

FIGURA 5. Plantio de mandioca em local desmatado no PNSD. Fonte: ICMBio.

Ao analisar o número de animais silvestres apreendidos, com total de 29 espécimes para o período de estudo, nota-se que a espécie que apresentou o maior número de registros foi Geochelone sp. (jabuti), com 26 registros, $89,66 \%$ do total (Figura 6). As demais espécies apresentaram 01 registro cada. Vale ressaltar que os dois indivíduos correspondentes às espécies Agouti paca (paca) e Caiman crocodilus (jacaretinga) estavam mortos.

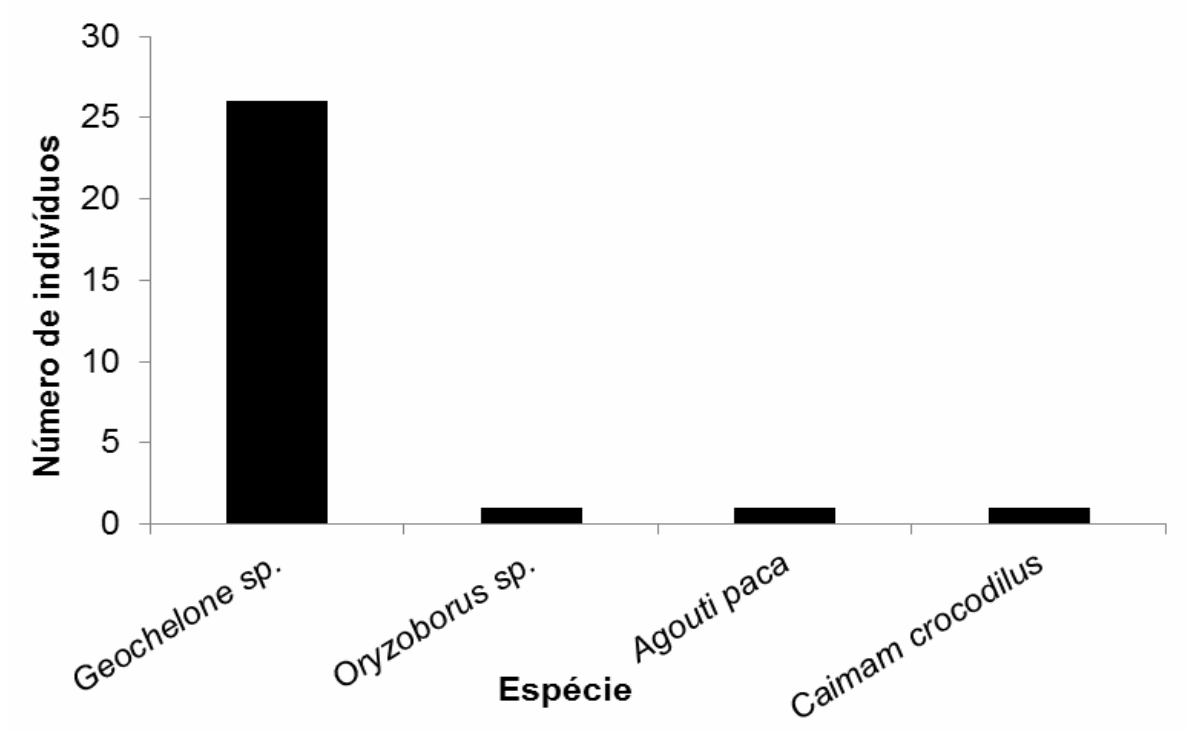

FIGURA 6. Total de unidades de animais apreendidos. Fonte: banco de dados do ICMBio 2011, no prelo.

As análises da quantidade total por $\mathrm{Kg}$ de carne apreendida (Figura 7) revelam um total de $92 \mathrm{Kg}$. Destes, $47 \mathrm{Kg}$ corresponderam a espécie Agouti paca (paca), $7 \mathrm{Kg}$ corresponderam a espécie Mazama spp. (veado), $3 \mathrm{Kg}$ de Tayassu sp. (porco do mato), $2 \mathrm{Kg}$ de carne de Tapirus terrestris (anta), $2 \mathrm{Kg}$ e $200 \mathrm{~g}$ de Cebus apella (macaco prego), $2 \mathrm{Kg}$ Dasyprocta sp. (cutia) e $800 \mathrm{~g}$ de Cebus albifronm (macaco-cairara). Os $28 \mathrm{Kg}$ restantes corresponderam a espécies cujas quantidades individuais não foram especificadas durante a apreensão. 


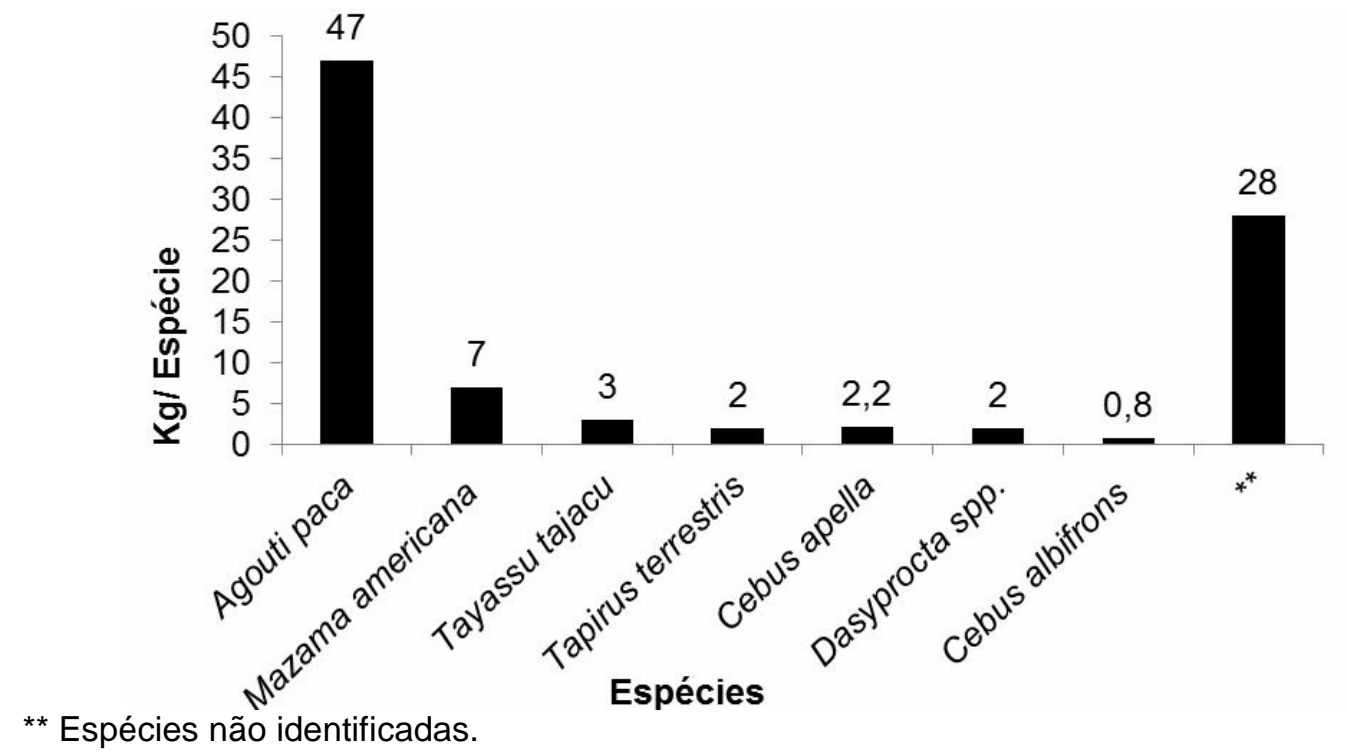

FIGURA 7. Quantidade em Kg/espécie apreendida durante fiscalização do ICMBio. Fonte: banco de dados do ICMBio 2011, no prelo.

ALMEIDA et al., (2011) constataram, durante levantamento na área Sul do PNSD, que tem havido redução da população de certos animais silvestres, como a paca (Agouti paca), o tatu (Dasypus novemvictus) e a anta (Tapirus terrestris). Os mesmos autores atribuem tal resultado, a uma série de fatores entre eles a diminuição da oferta de frutos das palmeiras à fauna, além da caça predatória e, ainda, em função da diminuição dos abrigos naturais dessas espécies. Além disso, a carne desses animais é utilizada para fins de subsistência e/ou comercialização. A conversão da floresta em áreas de agricultura intensiva, também, tem contribuído para o declínio dos recursos faunísticos, principalmente os animais que são caçados com finalidade para subsistência familiar (ALMEIDA, 2013).

Os animais vivos, assim como a carne silvestre apreendida, conforme consta nos autos, tiveram destinação diferenciada (Figuras 8 e 9). Os animais vivos foram soltos, como consta nos autos de apreensão, e a carne quando em boas condições, foi doada a instituições filantrópicas. A doação foi comprovada mediante o termo de destinação sumária existente nos autos.

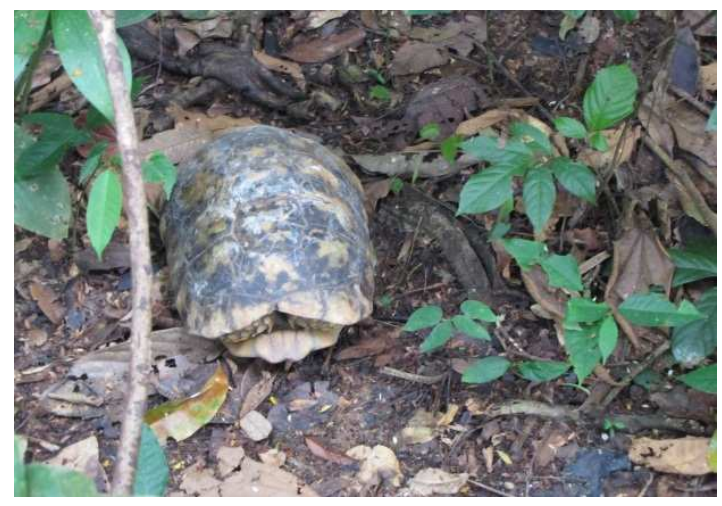

FIGURA 8. Soltura de Geochelone sp. Fonte: ICMBio.

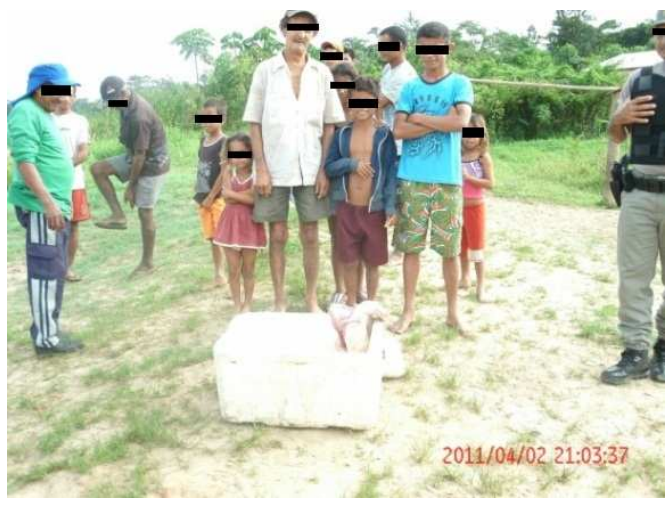

FIGURA 9. Doação de carne apreendida. Fonte: ICMBio. 
Ao avaliar qual o volume de madeira apreendido na área do PNSD no decorrer das operações, nota-se na Figura 10, que a espécie madeireira com maior volume apreendido foi o cedro (Cedrela sp.) com 21,53 $\mathrm{m}^{3}$, seguida do miratoá (Apuleia molaris) 2,38 $\mathrm{m}^{3}$, marfim (Balfourodendron riedelianum), com 1,88 $\mathrm{m}^{3}$, ingámel (Inga sp.) $1,73 \mathrm{~m}^{3}$ e marupá (Simarouba amara) com 1,38m³. As demais espécies, apresentaram valores inferiores a $1 \mathrm{~m}^{3}$ cada.

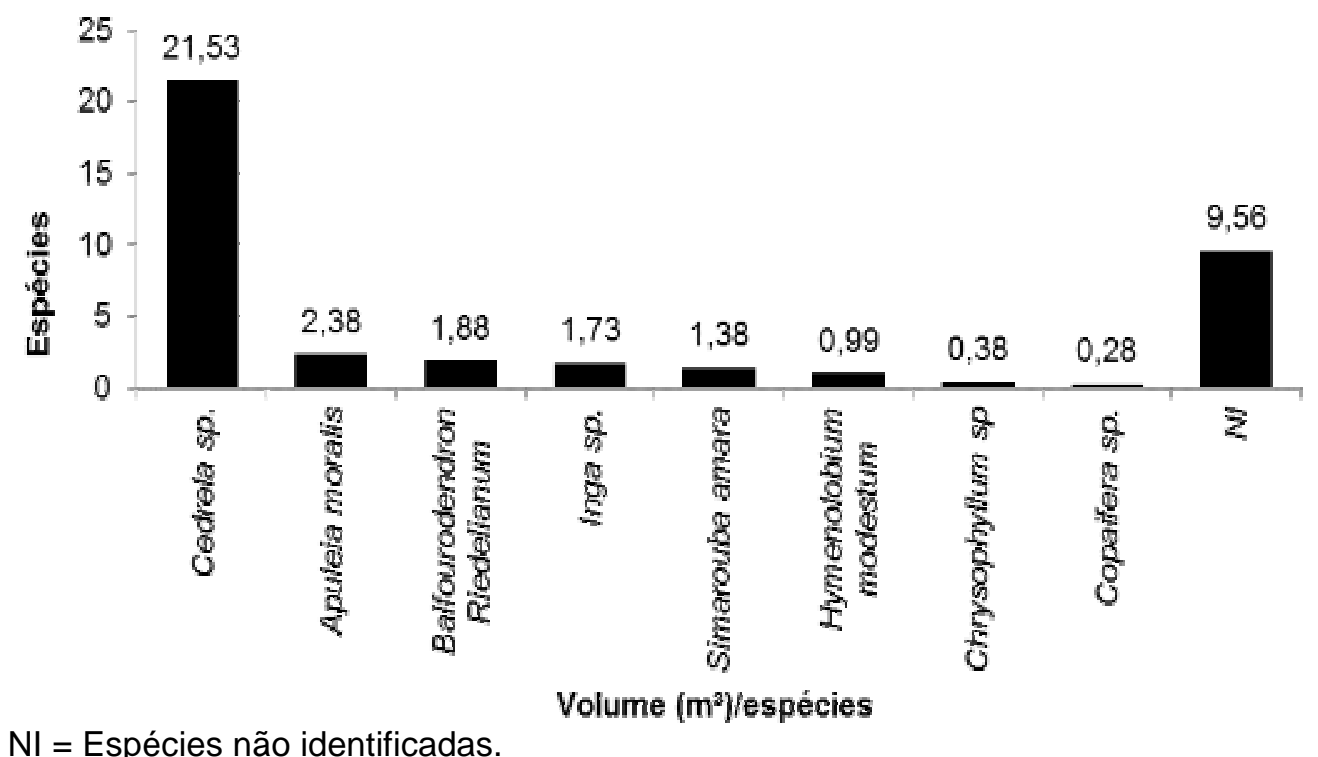

FIGURA 10. Espécies apreendidas durante fiscalização do ICMBio. Fonte: banco de dados do ICMBio 2011, no prelo.

O presente levantamento denotou ainda que durante o período de fiscalização foram apreendidos $41,43 \mathrm{~m}^{3}$ de madeira. Desse total, $28,18 \mathrm{~m}^{3}$ foram doados, 12,68 $\mathrm{m}^{3}$ foram destruídos e $0,57 \mathrm{~m}^{3}$ ficaram sob depósito com o próprio autuado (Figura, 11).

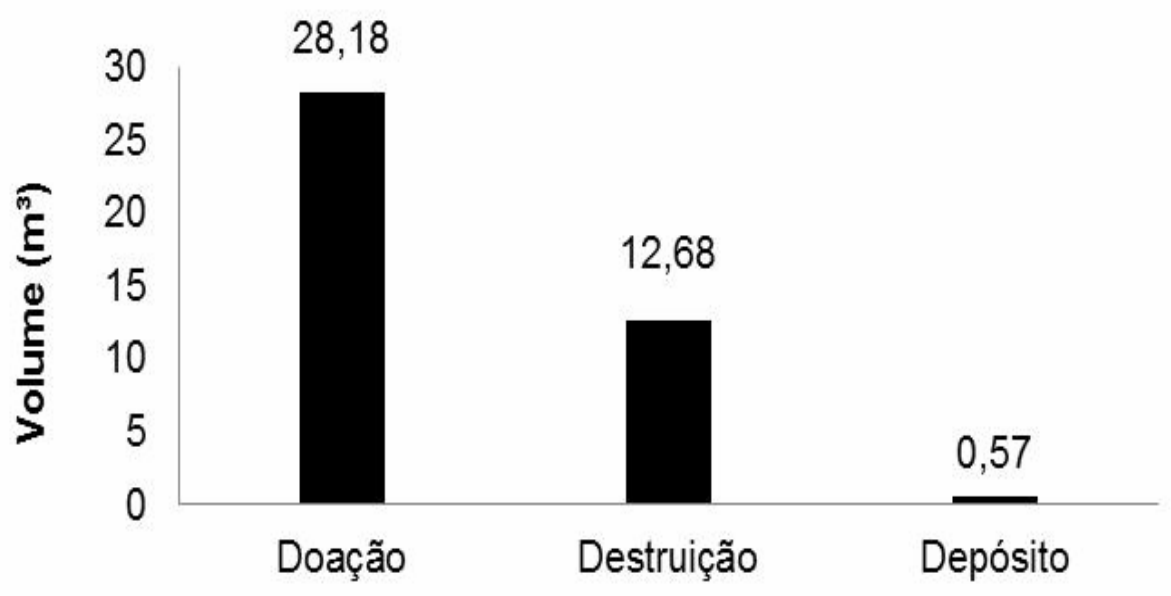

Tipo de destinação

FIGURA 11. Destinação da madeira apreendida durante as operações de fiscalização. Fonte: banco de dados do ICMBio 2011, no prelo. 
O valor total das multas, correspondentes aos Als lavrados durante as operações de fiscalização foi de $R \$ 1.371 .466,00$ (Tabela 2), a operação Sungarú foi a que apresentou maior valor de multas, ou seja, $R \$ 535.000,00$, seguida da Tamboriaco com $\mathrm{R} \$ 311.380,00$. Já os menores valores das multas foram observados na operação Capanauá com valor total de $\mathrm{R} \$ 39.716,00$.

TABELA 2. Valor total das multas/operação aplicadas em 2011.

\begin{tabular}{cc}
\hline Operação & Valor das Multas/ Operação \\
\hline Capanauá & $\mathrm{R} \$ 39.716,00$ \\
Ipú & $\mathrm{R} \$ 192.000,00$ \\
Mutum & $\mathrm{R} \$ 115.442,00$ \\
Pedernal & $\mathrm{R} \$ 177.928,00$ \\
Sungarú & $\mathrm{R} \$ 535.000,00$ \\
Tamboriaco & $\mathrm{R} \$ 311.380,00$ \\
TOTAL & $\mathbf{R} \$ \mathbf{1 . 3 7 1 . 4 6 6 , 0 0}$ \\
\hline
\end{tabular}

\section{CONCLUSÃO}

$\checkmark$ Os crimes contra a flora foram os mais ocorrentes no PNSD, durante os levantamentos, sendo representados principalmente por ações de desmatamento;

$\checkmark$ O maior volume de madeira apreendido correspondeu a extração de espécies nobres, com alto valor comercial o que pode denotar que existe atividade de comercialização ilegal de madeira na área;

$\checkmark$ Entre os crimes contra a fauna, houve predomínio da apreensão de animais silvestres;

$\checkmark$ Observou-se que a situação na área do PNSD é preocupante, uma vez que estes números dizem respeito, apenas ao que foi atuado pelo órgão fiscalizador, dessa maneira é indiscutível que ocorram muitos ilícitos, que não são registrados, devido às dificuldades na fiscalização.

$\checkmark$ Por se tratar de uma UC de proteção integral, legalmente não poderia haver populações dentro da unidade, vale, ainda, ressaltar que enquanto não houver a realocação e indenização das famílias do PNSD, bem como alternativas capazes de conciliar populações tradicionais com os recursos ambientais, atrelada há uma fiscalização mais efetiva a utilização e degradação dos recursos naturais do PNSD continuarão sendo uma prática contrária aos objetivos de proteção integral da unidade.

\section{REFERÊNCIAS}

ACRE, Governo do Estado do Acre. Programa Estadual de Zoneamento Ecológico-Econômico do Estado do Acre. Fase II, Escala 1:250.000. Documento Síntese. SEMA, Rio Branco. 2006.

ALMEIDA, G. S., Caracterização da nodulação e resposta de mudas de Inga spp. à inoculação com bactérias diazotróficas, no Parque Nacional Serra do Divisor, Amazônia Ocidental. Dissertação (Mestrado em Ciências Florestais) 
Universidade de Brasília, UnB, Brasília, 2013.

ALMEIDA, G. S., NASCIMENTO, L. O. N, ALMEIDA, A. da S., CARDOSO, J.F, LEAL, F.A., Capacidade de nodulação em Inga sp. de ocorrência na Amazônia Ocidental, Enciclopédia biosfera, Centro Científico Conhecer - Goiânia, v.9, n.17;2013.Disponível em:<http://www.conhecer.org.br/enciclop/2013b/CIENCIAS>.

ALMEIDA, G. S., SOUSA, P. O., OLIVEIRA, K. A., ALMEIDA, A. da S., SOUZA, A. M., Levantamento dos impactos ambientais causados pelo extrativismo na área sul do Parque Nacional Serra do Divisor - Acre. Enciclopédia Biosfera, Centro Científico Conhecer - Goiânia, v.7, n.13; 2011. Disponível em:< http://www.conhecer.org.br/enciclop/2011b/ciencias\%20ambientais>.

BARRETO, P. ARAÚJO, E., BRITO, B., A Impunidade de Crimes Ambientais em Áreas Protegidas Federais na Amazônia. Imazon, p. 55, Belém, 2009. Disponível em:<http://www.mma.gov.br/estruturas/225/_arquivos/12_a_impunidade_de_crimes_ ambientais_em_reas_protegidas_federais_na_amaznia_225.pdf >.

BRASIL. Lei no 9.985, de 18 de julho de 2000. Institui o Sistema Nacional de Unidades de Conservação da Natureza - SNUC, estabelece critérios e normas para a criação, implantação e gestão das unidades de conservação. Brasília, DF, 2000. Disponível em: <http://www.fundoambientalmacae.rj.gov.br/adm/pdfs/SNUC.pdf>. Acesso em: 09 de março de 2015.

BRASIL. Lei $\mathbf{n}^{\circ} \mathbf{9 . 6 0 5}$, de 12 de fevereiro de 1998. Dispõe sobre as sanções penais e administrativas derivadas de condutas e atividades lesivas ao meio ambiente, e dá outras providências. Disponível em: < http://www.planalto.gov.br/ccivil_03/leis/L9605.htm>. Acesso em 24 de maio de 2016.

BRASIL. Decreto $\mathbf{n}^{\circ} \mathbf{9 7 . 8 3 9}$, de 16 de junho de 1989. Cria o Parque Nacional da Serra do Divisor. Brasília, DF, 1989. Disponível em: <http://www.acordaoscarf.com.br/acordaos/3cc/1camara/acordaos/30131790_12877 3_11522000066200388_009. PDF>. Acesso em: 10 de março de 2015.

BRASIL. Decreto no 6.514, de 22 de julho de 2008a. Dispõe sobre as infrações e sanções administrativas ao meio ambiente, estabelece o processo administrativo federal para apuração destas infrações, e dá outras providências. Disponível em:< http://www.planalto.gov.br/ccivil_03/_ato2007-2010/2008/decreto/d6514.htm>. Acesso em 24 de maio de 2016.

BRASIL. Decreto no 6.686, de 10 de dezembro de 2008b. Altera e acresce dispositivos ao Decreto $\mathrm{n}^{-} 6.514$, de 22 de julho de 2008, que dispõe sobre as infrações e sanções administrativas ao meio ambiente e estabelece o processo administrativo federal para apuração destas infrações. Disponível em:< http://www.planalto.gov.br/ccivil_03/_ato2007-2010/2008/decreto/d6686.htm> Acesso em: 24 de maio de $201 \overline{6}$.

CAMELY. N. C., A reconfiguração do espaço agrário do acre como consequência do ENCICLOPÉDIA BIOSFERA, Centro Científico Conhecer - Goiânia, v.13 n.23; p. 408 2016 
ambientalismo ongueiro: A situação dos moradores do Parque Nacional da Serra do Divisor. XIX Encontro Nacional de Geografia Agrária, p. 1-27, 2009.

COSTA, L. M., Territorialidade e racismo ambiental: elementos para se pensar a educação ambiental crítica em unidades de conservação. Pesquisa em Educação Ambiental, v. 6, n. 1 - p. 101-122, 2011. Disponível em:< http://www.revistas.usp.br/pea/article/view/55936/59322>.

FONSECA, A. M. T., VALENTE, L. M., LOPES, M. C., Diagnóstico dos crimes contra a flora a partir das ações impetradas pelo ministério público federal. Revista Eletrônica de Direito, v.8, n. 1/2013. Disponível em:< http://cascavel.ufsm.br/revistas/ojs-2.2.2/index.php/revistadireito/article/view/8140> DOI: $10.5902 / 19813694$.

KEMF, E. (Org.), Indigenous Peoples and Protected Areas: The Law of Mother Earth. London: Earthscan, 1993.

LEMOS, R. M., A eficácia da aplicação da lei de crimes ambientais para a proteção do meio ambiente no litoral sul da Bahia. Dissertação mestrado (conservação da biodiversidade e desenvolvimento sustentável) Instituto de Pesquisas Ecológicas, Uruçuca, Bahia, 2013.

MORATO, E. F., AMARANTE, S. T., SILVEIRA, O. T., Avaliação ecológica rápida da fauna de vespas (Hymenoptera: Aculeata) do Parque Nacional da Serra do Divisor, Acre, Brasil. Acta Amazônica. v.38, n.4, 2008. Disponível em:< http://www.scielo.br/pdf/aa/v38n4/v38n4a25.pdf>.

ORTEGA, G. P.; QUEIROZ, A. M. de.; VALENTE, R. A. da S.; ZUMBA JUNIOR, F. $P$. Crimes ambientais cometidos contra a flora no município de Cruzeiro do Sul-Acre de 2003 a 2010. Enciclopédia Biosfera, Centro Científico Conhecer - Goiânia, v.8,

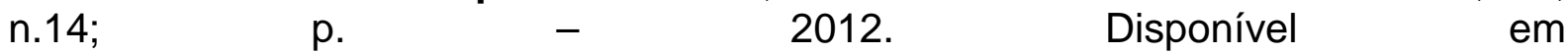
<http://www.conhecer.org.br/enciclop/2012a/ambientais/crimes.pdf>

PLATIAU, A. F. B., O Brasil na governança das grandes questões ambientais contemporâneas, Instituto de Pesquisa Econômica Aplicada, Brasília, 2011.

SILVA, M. do. S. F da; SOUZA, R. M. Territórios protegidos e arenas de conflito nas unidades de conservação de uso sustentável em Sergipe, Brasil. Scripta Nova Electrónica de Geografía y Ciencias Sociales Universidad de Barcelona. V. XVII, n. 445, 20 de julho de 2015. Disponível em: < http://www.ub.edu/geocrit/sn/sn445.htm>.

SOS AMAZÔNIA. Plano de Manejo do Parque Nacional da Serra do Divisor (PNSD). Rio Branco: SOS Amazônia/ the nature conservancy/ USAID. 1998. 600 p.

VERISSIMO, A.; ROLA, A.; SOUTO MAIOR, A.P.C.; MONTEIRO, A.; BRITO, B.; SOUZA JÚNIOR, C.; AUGUSTO, C. C.; CARDOSO, D.; CONRADO, D.; ARAÚJO, E.; RICARDO, F.; RIBEIRO, J.; LIMA, L. M. de.; RIBEIRO, M.B.; VEDOVETO, M.; MESQUITA, M.; BARRETO, P. G.; SALOMÃO, R.; FUTADA, S. de. M. Áreas ENCICLOPÉDIA BIOSFERA, Centro Científico Conhecer - Goiânia, v.13 n.23; p. 409 
protegidas na Amazônia Brasileira: Avanços e Desafios. Belém: Imazon; São Paulo: Instituto Socioambiental, 87p. 2011. Disponível em < http://fasamazonas.org/versao/2012/wordpress/wp> 